\title{
Erratum to: Formal ontologies and strategic environmental assessment. A case study: the municipal land use plan of Genoa
}

Giampiero Lombardini*

\section{Erratum to: City Territ Archit (2016) 3:8 \\ DOI 10.1186/s40410-016-0037-x}

In the publication of this article (Lombardini 2016), the following acknowledgment failed to be included:

'This article is the outcome of a research project coordinated by Prof. M. Besio, Department of Sciences for Architecture, Genoa-I. The research aimed to develop a strategic environmental assessment for the Municipality of Genoa, Italy. All images were produced by the Municipality of Genoa-UrbaLab, Silvia Capurro, Anna Mara Colombo and Cristina Giusso. The author has acquired permission to include them in the article.

The online version of the original article can be found under doi:10.1186/s40410-016-0037-x.

Published online: 12 September 2016

\section{Reference}

Lombardini G (2016) Formal ontologies and strategic environmental assess-

ment. A case study: the municipal land use plan of Genoa. City Territ Archit 3:8. doi:10.1186/s40410-016-0037-x

*Correspondence: g.lombardini@arch.unige.it

Department of Sciences for Architecture, Polytechnic School, University

of Genoa (I), Stradone Sant'Agostino, 37, Genoa, Italy 